Ciência e Natura, Santa Maria v.38 n.2, 2016, Mai.- Ago. p. 941 -951

Revista do Centro de Ciências Naturais e Exatas - UFSM

ISSN impressa: 0100-8307 ISSN on-line: 2179-460X

\title{
CIÊNCIA'NATURA
}

\section{Comportamento do consumidor de produtos ecológicos: um comparativo entre duas cidades da região fronteira oeste do Rio Grande do Sul}

Of ecological products consumer behavior: a comparison between two cities of the border west of the RS region

\author{
Laura da Silveira Leal e Andressa Rocha Lhamby e Victor Paulo Kloeckner Pires \\ Universidade Federal do Pampa , RS Brasil \\ laura-leal@hotmail.com; andressalhamby@unipampa.edu.br; victor@sgnet-rs.com.br
}

\begin{abstract}
Resumo
Para satisfazer as necessidades e desejos humanos é necessário trabalhar com mercados e realizar trocas, isto chama-se Marketing. Devido às problemáticas ambientais como o efeito estufa, degradação da natureza, escassez dos recursos, entre outros, surgiu um novo conceito dentro do marketing, o Marketing Ambiental, que atende as necessidades e os desejos humanos, porém busca não prejudicar o meio ambiente natural, e mesmo assim atinge os objetivos das empresas. Nesse contexto, através de questionários aplicados nos clientes e funcionários dos supermercados COTRISEL de Vila Nova do Sul/ RS e Big Max de São Gabriel/ RS, buscou-se analisar e comparar o comportamento de consumidores e dos próprios empregados frente aos hábitos de consumo e elementos influenciadores do comportamento de compra, definir o marketing e seus componentes, analisando os contextos em que mercados são segmentados, definindo o público-alvo, identificando e descrevendo as variáveis envolvidas no processo decisório de compra, porém concluiu-se que, primeiramente, deve-se trabalhar a educação ambiental dos funcionários e clientes dos supermercados e posteriormente desenvolver estratégias de Marketing Ambiental.
\end{abstract}

Palavras-chave: Ambiental. Marketing. Sustentabilidade. Público. Organização.

\begin{abstract}
To meet human needs and desires is necessary to work with markets and carry trade, this is called Marketing. Due to environmental problems such as global warming, nature degradation, resource scarcity, among others, a new concept in marketing, Environmental Marketing, which meets the needs and human desires, but search does not harm the natural environment, and yet achieves the objectives of the companies. In this context, through questionnaires on customers and employees of COTRISEL supermarkets in Vila Nova do Sul / RS and Big Max of São Gabriel / $R S$, aimed to analyze and compare the behavior of consumers and employees themselves forward to spending habits and influencers elements of buying behavior, define marketing and its components, analyzing the contexts in which markets are segmented, defining the target audience, identifying and describing the variables involved in the decision-making purchase process, but it was concluded that the primary responsibility for If work environmental education of employees and customers of supermarkets and subsequently develop Environmental Marketing strategies.
\end{abstract}

Keywords: Environmental, Marketing, Sustainability, Public, Organization. 


\section{Introdução}

Nickels e Wood (1999, p. 4) dizem que “Marketing é o processo de estabelecer e manter relações de troca mutuamente benéficas com clientes e outros grupos de interesse". Bennett (1995 apud CHURCHILL; PETER, 2000, p. 4) cita Marketing como "o processo de planejar e executar a concepção, estabelecimento de preços, promoção e distribuição de ideias, bens e serviços a fim de criar trocas que satisfaçam metas individuais e organizacionais”. Las Casas (1993) afirma que o marketing é uma área que reúne práticas ligadas às relações de trocas, visando à satisfação das necessidades e desejos dos consumidores, tentando atingir objetivos e metas de empresas ou indivíduos e tendo sempre consideração com o meio ambiente e atuação e o impacto dessas relações com sociedade. Segundo Kotler e Armstrong (1993, p.5), “Marketing significa trabalhar com mercados para conseguir trocas com o propósito de satisfazer as necessidades e desejos humanos". Ele ainda comenta que para se vender bens de consumo com facilidade é preciso fazer a identificação das necessidades do consumidor, criar bons produtos e estabelecer seu preço ideal, fazendo a sua distribuição e promoção. O mesmo autor, em 1999, melhor define Marketing como "um processo social e gerencial pelo qual indivíduos e grupos obtêm o que necessitam e desejam através da criação, oferta e troca de produtos de valor com outros".

As necessidades, os desejos humanos e a demanda são os pontos iniciais do Marketing. Necessidade humana é a carência de satisfação básica, como alimentação, abrigo, roupa, segurança, entre outros, e não são criados pela sociedade ou empresas. Quando as necessidades básicas ou humanas são supridas, surgem os desejos, que são muitos em relação às outras, pois esses são influenciados por igrejas escolas, famílias, empresas e instituições sociais. E quando se pode comprar os desejos, chama-se de demanda (KOTLER; ARMSTRONG, 1993; KOTLER, 2009).

\subsection{O Marketing Ambiental, o comportamento do consumidor e os novos padrões de consumo}

Para uma empresa obter sucesso em seus negócios alguns elementos são fundamentais, tais como um bom administrador, funcionários dedicados, possuir um plano de negócio e oferecer serviços de qualidade. Também recomenda-se estar atento as necessidades e desejos dos consumidores que estão sempre se modificando, como Etzel et al. (2001) falam que o trabalho dos profissionais do marketing torna-se cada vez mais difícil devido as rápidas mudanças dos desejos dos consumidores, que antigamente não acontecia. Os padrões socioculturais como, estilo de vida, valores, crenças estão mudando.

Setores como alimentação, habitação, vestuário, transporte, poupança, saúde, educação, entre outros, tiveram altos e baixos, Pode-se afirmar que essas mudanças se devem principalmente as mudanças de hábitos das pessoas (COBRA, 1992). Com essas mudanças houve um aumento significativo do consumo, e se a população consome mais, consequentemente a empresa produz mais, o que demanda a utilização dos recursos disponíveis do ambiente físico. Segundo Cobra (1992, p. 136), “o homem depreda a natureza, não conserva e não recicla seus materiais. A qualidade de vida cai assustadoramente. A natureza, diante da ação devastadora do homem, não consegue recompor-se". $\mathrm{O}$ autor ainda cita quatro tendências do ambiente 
físico que os profissionais do marketing ainda não estão conscientes que pode ocorrer:

- Potencial de escassez de certas matériasprimas

- Instável custo da energia

- Crescentes níveis de poluição

- Mudança no papel do governo na proteção ambiental

Estamos vivendo em uma era de degradação ambiental, aumento da população, a fome e a pobreza se tornando cada vez mais comuns, e estes fatos estão mudando o pensamento das pessoas, que acabaram exigindo um novo conceito de marketing, o Marketing Ambiental ou Ecológico, que para Dias (2009, p.73), é aquele que "busca formas de atender aos ilimitados desejos e necessidades dos consumidores, sem prejudicar o meio ambiente natural, e ao mesmo tempo realizando os objetivos de comercialização das organizações”. Já Baker (2005) define marketing ambiental ou verde como: "o processo holístico responsável por identificar, antecipar e satisfazer as necessidades de clientes e da sociedade, de um modo lucrativo e sustentável".

\subsection{Consumidores e produtos ecológicos}

Atualmente a população está mais preocupada com a qualidade de vida do que simplesmente no consumo de produtos. E como uma organização não consegue satisfazer todos os desejos de seus consumidores, uma empresa deve reunir todas as necessidades e aspirações de um determinado grupo e empenhar-se a oferecer os melhores produtos e serviços para seu chamado mercado-alvo, que são "um ou mais grupos específicos de potenciais consumidores para os quais uma organização direciona seu programa de marketing" (BERKOWITZ et al.,2003, p. 11).

Como já comentado, os problemas ambientais estão se agravando com o passar do tempo. Uma empresa que não se preocupa com o meio ambiente nos dias de hoje, é uma empresa que não tem responsabilidade com a qualidade de vida, por isso uma das maiores problemáticas enfrentadas por essas nos seus negócios acaba sendo o meio ambiente. Ele está presente no marketing em todas as decisões desde o planejamento do produto até as relações públicas. "Os gerentes tem de lidar com diferentes aspectos da ecologia a obsolescência programa, a poluição, o lixo reciclável e a conservação dos recursos" (BOONE; KURTZ, 1998, p. 80). Devido a essas questões, as empresas associam os seus projetos sociais de preservação ao meio ambiente, fabricação de produtos ambientalmente corretos, separação e reciclagem do lixo entre outros, com a propaganda da empresa. Assim, podem aliar a preocupação ambiental á teoria prática do marketing (BAKER, 2005). A mídia, também tem divulgado cada vez mais matérias sobre o meio ambiente e o que as ações predatórias do homem causam. E isso tem motivado as pessoas a tomarem atitudes que não agridem a natureza, como a compra de produtos ambientalmente corretos. Para esses consumidores denominam-se consumidores verdes ou ecológicos. A compra pode ser feita de duas maneiras: quando um consumir escolhe um determinado produto ele opta por um semelhante, porém ecologicamente correto, ou quando um produto agride o meio ambiente o consumidor recusa-se a fazer a compra (DIAS, 2009).

O mesmo autor cita algumas características do perfil desse novo consumidor, que sempre faz suas compras pesquisando por produtos que julgue não 
prejudicar a natureza ou que tenha menos impacto no meio ambiente que produtos similares. Esses consumidores também estão dispostos a pagar mais caro por um produto ecológico porque sabem que seu preço está associado ao seu valor social. Dias (2009, p.118) caracteriza o produto como "bens e serviços oferecidos ao mercado para satisfazer as necessidades e aos desejos dos clientes". Os produtos podem ser bens, serviços ou ideias. E a muitos desses produtos pode-se agregar o adjetivo ecológico, que se refere ao ciclo de vida de um produto.

\footnotetext{
E, desse modo, um produto será ecológico quando cumprir as mesmas funções dos produtos equivalentes, mas causando um prejuízo perceptivelmente menor ao longo de todo o seu ciclo de vida, tanto na produção, como no consumo e na eliminação final (DIAS, 2009, p.118)
}

Para a definição de um produto ecológico é preciso considerar vários fatores, como os materiais que o compõem, os processos produtivos envolvidos na sua produção, como ele é utilizado pelos consumidores, sua geração de resíduos na distribuição e transporte e sua reutilização ou eliminação.

Contudo, um produto verde é aquele que oferece os mesmos benefícios de um produto similar, porém não causa tantos danos ao meio ambiente durante todo o seu ciclo de vida.

Dias (2009) classifica os produtos ecológicos como:

- Produtos feitos de bens recicláveis,

- Produtos que podem ser reciclados ou reutilizados,

- Produtos eficientes, que economizam recursos e reduzem o impacto ambiental,

- Produtos com embalagens ambientalmente responsáveis,
- Produtos orgânicos,

- Serviços que alugam ou emprestam produtos,

- Produtos certificados, que atingem ou excedem critérios ambientalmente responsáveis.

$\mathrm{Na}$ comercialização dos produtos o profissional do marketing não deve se preocupar apenas com a fabricação do produto, mas sim com outros aspectos que estão ligados as questões ambientais, como a introdução de novos produtos, melhoria dos produtos existentes e eliminação de produtos existentes e que não sejam rentáveis em curto prazo. (DIAS, 2009).

Portanto, a problemática envolvida no presente estudo centrou-se em saber se os consumidores das empresas objetos de analises, em seu processo de compra, buscavam por produtos que se classificariam como "ecologicamente corretos", bem como identificar os fatos que os levam ao processo decisório da compra que efetivamente levavam a efeito.

Nesse contexto, o tema proposto torna-se proeminente em um momento em que as questões ambientais ganham relevância e, sob o ponto de vista organizacional, da necessidade das empresas virem a adaptar-se aos desejos de seus consumidores, ajustando-se as novas exigências do mercado e, em ultima analise utilizarem esses diferenciais como vantagem competitiva.

A população em estudo foram os funcionários e clientes dos Supermercados COTRISEL de Vila Nova do Sul / RS e Big Max de São Gabriel - RS e o número total de entrevistados foram 200 consumidores. 


\section{Metodologia}

Para a realização deste artigo, o instrumento de coleta de dados abordou o tema qualitativamente, que, conforme Leal e Souza (2006) tem como objetivo coletar dados do ambiente natural que é a fonte e o pesquisador é o instrumento-chave. Nesse processo a interpretação de fenômenos e a atribuição de significados servem de base e não é preciso fazer o uso de métodos e técnicas estatísticas. O estudo caracteriza-se por ser exploratório e descritivo. Os mesmos autores explicam:

- Pesquisa exploratória: visa construir hipóteses ou tornar o problema explicito. Através de entrevistas é feito um estudo de caso.

- Pesquisa descritiva: são coletados dados de determinada população e não há interferência do pesquisador nos registros, análises, classificação e interpretação dos resultados. Aqui, estão incluídas as pesquisas feitas nas ciências humanas e sociais como, por exemplo, pesquisas de opinião, mercadológicas. Utiliza técnicas padronizadas de coleta de dados como o questionário.

Leal e Souza (2006) completam: “A pesquisa descritiva é juntamente com a pesquisa exploratória, a que habitualmente realiza o pesquisador social preocupado com a atuação prática”. A pesquisa qualitativa tem como foco principal da abordagem o processo e seu significado. Ela envolve ouvir a opinião das pessoas sobre determinado assunto, discute os temas em seu cenário natural, interpretando as respostas das pessoas entrevistadas. Preserva a complexidade do comportamento humano e utiliza uma abordagem holística.

Leal e Souza (2006) destacam as vantagens e desvantagens da aplicação desse tipo de pesquisa: As vantagens é a compreensão da forma de vida, registro do comportamento não verbal, inclusão de informações não esperadas e é culturalmente apropriado. Porém as desvantagens ou limitações são: consome muito tempo, amostragem pequena, necessita de entrevistados bem treinados e o processamento não permite generalização de modo automático.

As perguntas que compuseram os questionário foram elaboradas com base no livro de Dias (2009) e eram semi-abertas, possuíam duas ou mais alternativas de resposta e apenas uma resposta possível, e perguntas abertas, que também são constituídas de duas ou mais alternativas, mas após assinalar uma delas o entrevistado poderia complementar a sua resposta.

Assim, este estudo que teve por finalidade diagnosticar o comportamento das pessoas que frequentam os Supermercados COTRISEL (Vila Nova do Sul/ RS) e Big Max (São Gabriel/ RS) frente aos requisitos e propostas do marketing ambiental. Previamente, foram aplicados os questionários na cidade de Vila Nova do Sul/ RS e a seguir verificouse a necessidade de se comparar os dados obtidos com mais algum cenário, com a intenção de, obter parâmetros de comparação. Logo, escolheu-se o município de São Gabriel/ RS.

\section{Resultados e discussão}

Averiguando-se os resultados encontrados através dos questionários, verificou-se nas entrevistas realizadas em ambos os municípios que a maioria dos 
consumidores eram mulheres. Na COTRISEL elas tinham idade entre 36 e 45 anos (58\%), já no Big Max possuíam idade entre 15 e 25 anos (57\%). Na COTRISEL possuíam apenas o ensino fundamental (41\%) e no Big Max ensino médio (71\%), moravam nas referidas cidades, área urbana, frequentam a COTRISEL mais de 3 vezes por semana (35\%), e frequentavam o Big Max menos de três vezes por semana (36\%). Quando perguntados se já tinham ouvido falar em Marketing Ambiental, na COTRISEL mais da metade dos entrevistados não tinha conhecimento sobre o assunto, já no Big Max foi ao contrário, maior parte dos entrevistados já tinham ouvido falar em Marketing Ambiental, como segue Gráfico 1:

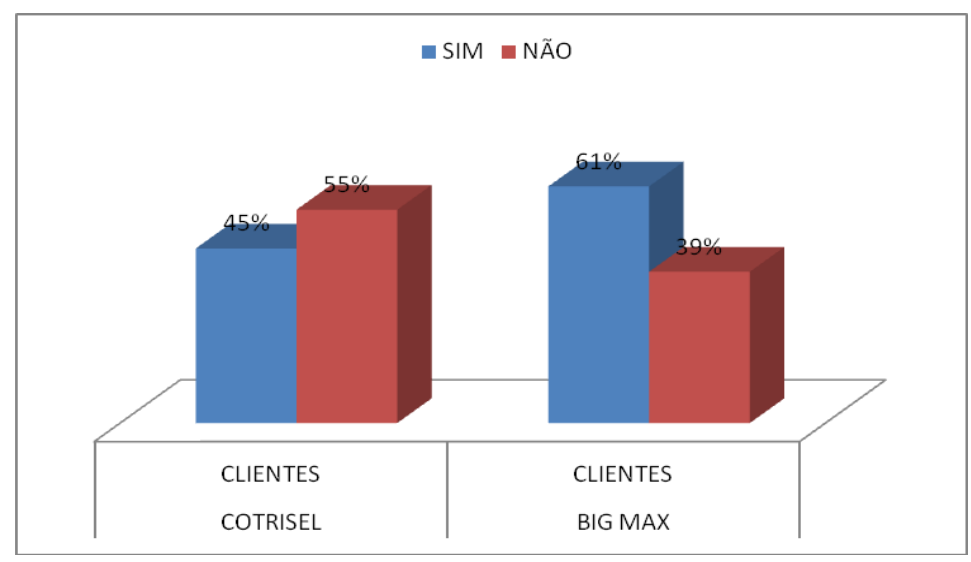

Gráfico 1 - Você já ouviu falar em Marketing Ambiental?

A próxima pergunta era: o que influenciava a sua decisão na hora da compra? Dos dois supermercados a maior parte dos consumidores responderam a qualidade. Quando perguntados se as propagandas feitas por empresas, sobre a produção e venda de produtos ambientalmente corretos interferem na sua decisão de compra, mais da metade respondeu que sim. A televisão foi o meio mais citado pelos entrevistados, por onde tomaram o conhecimento de produtos ambientalmente corretos. $\mathrm{Na}$ pergunta seguinte grande parte dos entrevistados afirmou não verificar se um produto não agride a natureza, mas estão dispostos a pagar mais por um produto verde. A empresa mais citada em Vila Nova do Sul, que mostra sua preocupação com o meio ambiente foi a Rede Vivo e em São Gabriel foi Natura.
Com os funcionários na COTRISEL houve um equilíbrio entre o número de homens e mulheres $\mathrm{e}$ no Big Max a maioria eram mulheres, nos dois lugares a maioria possui idade entre 15 a 25 anos que possui ensino médio e moram na área urbana de suas cidades. Nesse grupo de entrevistados nas duas cidades grande parte já ouviram falar de Marketing Ambiental, também compram produtos pela sua qualidade, que as propagandas feitas por empresas sobre a produção e venda de produtos ambientalmente corretos interferem nas suas decisões de compra.

Quando perguntados se na hora da compra verificam se o produto é ambientalmente correto? Houve um empate entre os trabalhadores do supermercado COTRISEL, já os trabalhadores do Big Max disseram que não, a maioria nas duas empresas 
disseram que identificam o produto pelos símbolos de reciclagem na embalagem e estariam dispostos a pagar mais por um produto ambientalmente correto.

Fazendo uma análise mais específica, comparando clientes e funcionários dos dois supermercados em questão pode-se dizer que os entrevistados da cidade de São Gabriel possuem maior grau de instrução, são pessoas mais jovens e já ouviram falar em Marketing Ambiental. Porém, houveram algumas divergências nas duas empresas entre suas respostas. Eles afirmam comprar um produto pela sua qualidade, mas quando perguntados se as propagandas feitas pelas empresas sobre produtos ambientalmente corretos interferem em sua decisão de compra, a maioria respondeu que sim.
Nesse caso, se as propagandas realmente interferissem nas suas decisões de compra, os clientes deveriam responder que compram seus produtos conforme a preocupação ambiental da empresa. Mas de qualquer forma, estão dispostos a pagar mais por um produto ambientalmente correto. Isso mostra que as pessoas que frequentam o supermercado COTRISEL e Big Max têm vontade de fazer algo pelo meio ambiente, mas não sabem como, porque não possuem o conhecimento necessário para tanto. Em outra pergunta, questionava-se se quando compravam algum produto verificavam se ele era ambientalmente correto, os entrevistados das duas cidades tanto quanto clientes e trabalhadores, exceto os de Vila Nova do Sul, a maioria afirmaram que não, como pode-se observar no gráfico 2 :

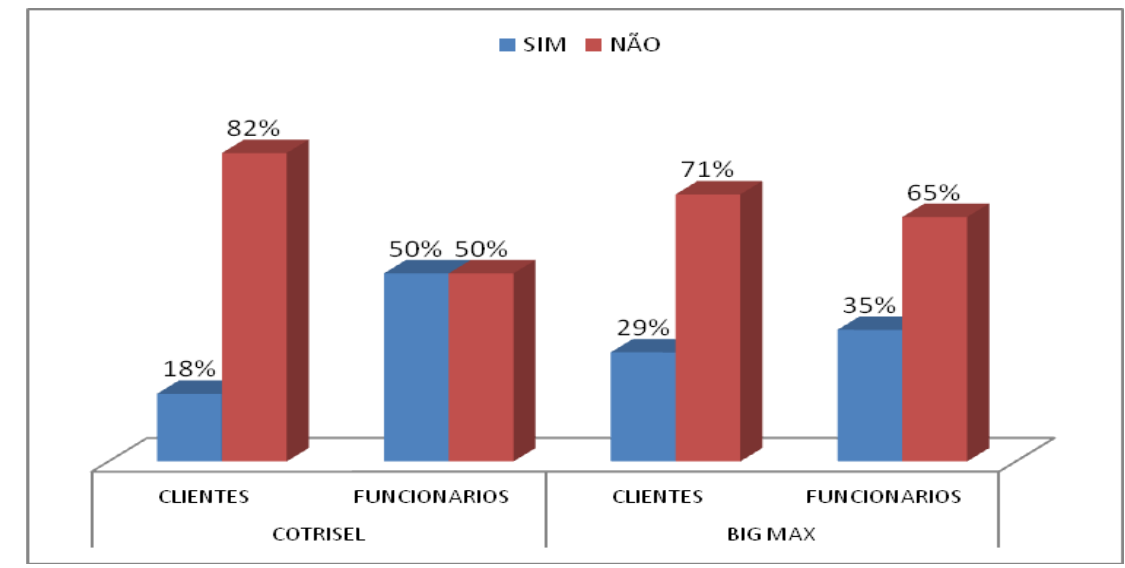

Gráfico 2 - Quando compra algum produto você verifica se ele é ambientalmente correto?

É possível observar que há uma porcentagem de pessoas que responderam que verificam se o produto é ambientalmente correto. Só que quando questionados como identificavam se um produto é ambientalmente correto as respostas foram as seguintes conforme gráfico 


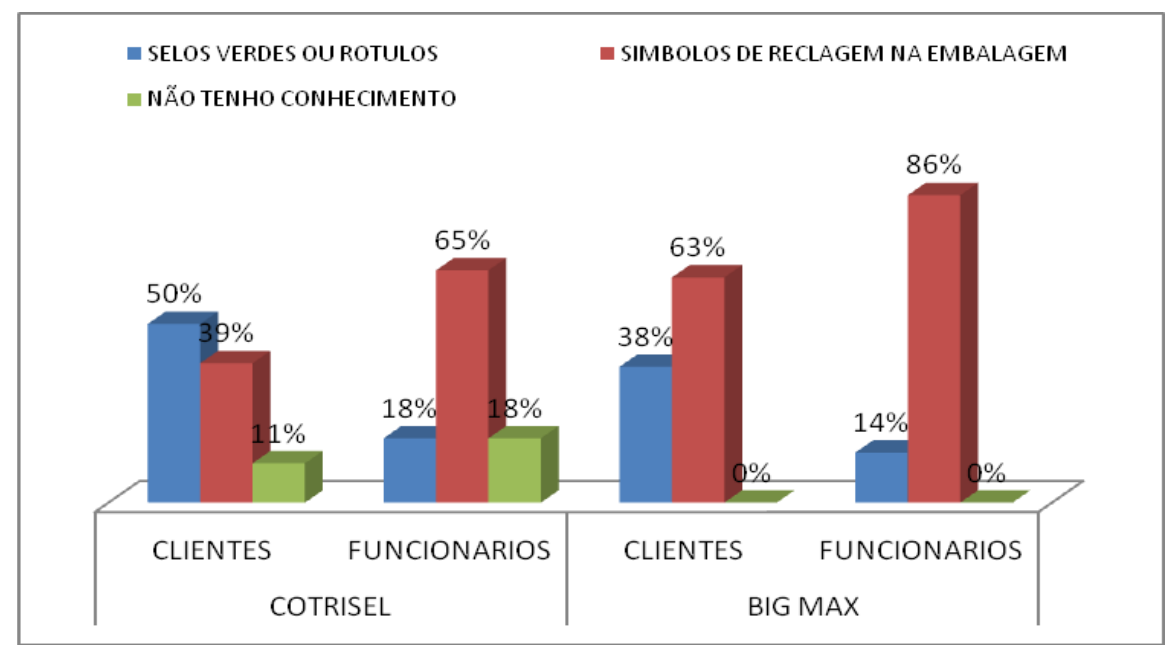

Gráfico 3 -Como você identifca o produto?

Então observou-se que algumas pessoas não possuem nenhum conhecimento sobre esse assunto e acabam divergindo nas respostas. Outra questão a se ressaltar está relacionada com a seguinte pergunta:
Você conhece alguma empresa ou produto que mostre a sua preocupação com o meio ambiente? Seguem abaixo as respostas dos dois grupos das duas cidades conforme os gráficos 4 e 5 :

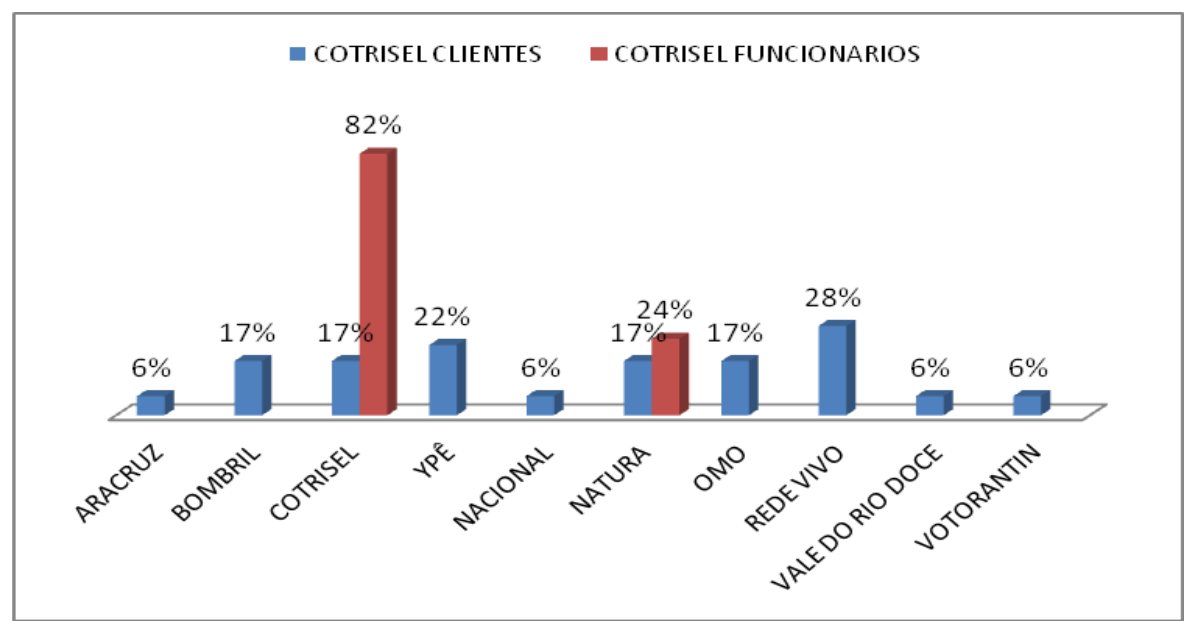

Gráfico 4 - Qual empresa ou produto que você conhece que mostra preocupação com o meio ambiente?

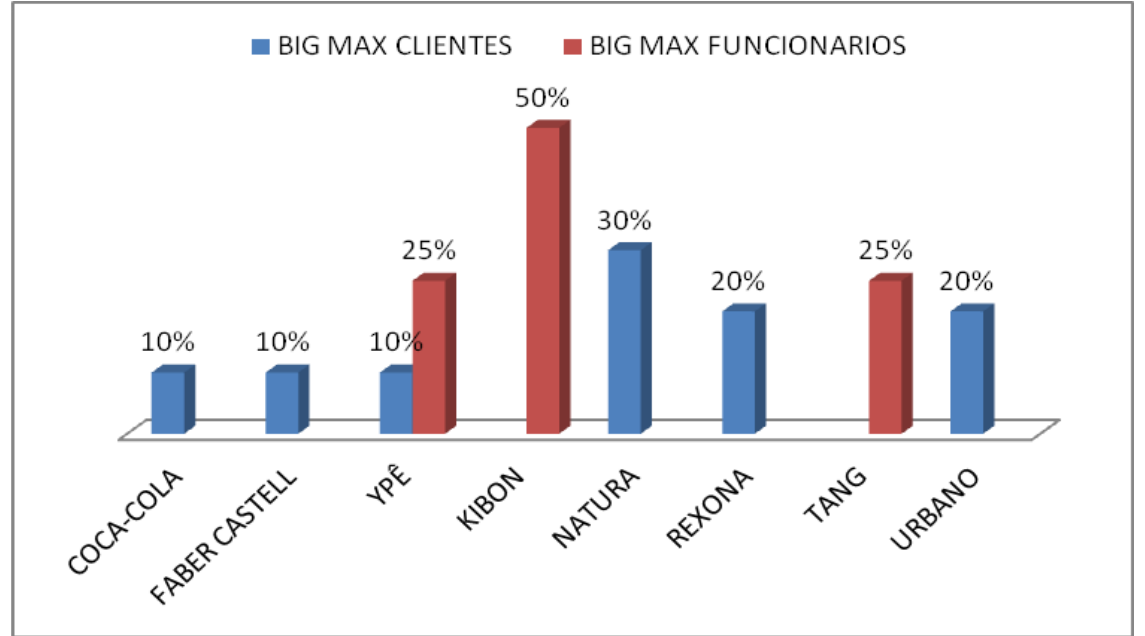

Gráfico 5: Qual empresa ou produto que você conhece que mostra preocupação com o meio ambiente? 
Das pessoas que responderam que conhecem uma empresa que se preocupa com meio ambiente, estavam empresas que não associam seus produtos com a preocupação com o meio ambiente, como Omo e Tang. Logo, foi perguntado como os entrevistados tinham tomado conhecimento desse produto, algumas pessoas responderam ter visto na televisão, mas a Aracruz, Urbano e a COTRISEL, não possuem propagandas na televisão.

Assim, verifica-se que tanto clientes quanto funcionários confundem na maioria das vezes seus conhecimentos relacionados às questões ambientais com o Marketing Ambiental. Pode-se perceber também que os dois grupos dos dois supermercados estão dispostos a pagar mais por um produto ambientalmente correto, mas infelizmente não possuem conhecimento necessário para fazê-lo. Também se ressalta que o grau de escolaridade apresentado nos clientes da cidade de São Gabriel pode ter influenciado em algumas respostas como o conhecimento do Marketing Ambiental. Pode-se citar outra resposta com relação aos funcionários da COTRISEL ao serem questionados sobre o conhecimento de uma empresa que mostre sua preocupação com meio ambiente ser indicado a COTRISEL. O fato de ser empregados e estar em contato direto com as ações da empresa, os funcionários confundem ações de gestão ambiental com Marketing Ambiental, que a empresa não realiza.

Contudo, para que as empresas COTRISEL e Big Max realizem mais ações focadas ao Marketing Ambiental, deve-se aproveitar a constante mudança de hábitos de consumo dos clientes, influenciando em suas decisões de compra. Como a segmentação de mercado da empresa é feita com o marketing local, é necessário usar-se primeiramente da ferramenta de educação ambiental. Incentivando os clientes a fazer compras conscientes, mostrando-lhes da importância de adquirir produtos verdes, reciclar e reutilizar produtos irá mudar seus hábitos de consumo rapidamente, pois foi mostrado nas pesquisas que eles estão dispostos a isso. Deve-se fazer que o cliente reconheça uma necessidade, mas disponibilizando-o meios para que ele possa buscar informações e avalie alternativas para determinar sua escolha. Logo, é necessário usar as influências do marketing, como o produto, desenvolvendo produtos que chame a atenção do consumidor dando-lhes informações que o convença da utilização deste. O preço é outro fator importante, mas, nesse caso, conforme a pesquisa os clientes estão dispostos a pagar mais por um produto que não agride a natureza, mas é muito importante que o preço não seja tão mais elevado que um produto similar.

\section{Conclusão}

Para propor medidas de mudanças para as empresas COTRISEL e Big Max seriam necessários mais estudos acerca do assunto e conhecer ainda mais os clientes. Por isso, sugere-se algumas mudanças relacionadas à gestão ambiental que trabalha a educação ambiental para alcançar os objetivos do marketing. As sugestões são as seguintes:

- Oferecer cursos de capacitação para os funcionários, onde iriam aprender sobre sustentabilidade, reciclagem, reutilização e separação correto do lixo.

- Usar os meios de comunicação que a COTRISEL e o Big Max dispõem para dar dicas sobre o meio ambiente e como preservá-lo.

- Os dois supermercados poderiam fechar um acordo com as prefeituras de suas cidades, e aos domingos nas ruas promoveriam ações relacionadas ao meio ambiente. Como palestras, oficinas de reciclagem, coleta de 
materiais para doações a cooperativas, aprendizagem de reutilização de produtos, entre outros.

- Nesse acordo com as prefeituras, também poderia incluir trabalhos dentro das escolas da cidade. Pelo menos uma vez por mês poderiam levar ensinamentos sobre a natureza e mostrar um pouco mais do seu trabalho para as crianças, que logo passariam a seus pais.

Por fim, existem muitas ações que podem ser tomadas para promover as empresas e ajudar no ensinamento dos seus clientes. Com a escassez dos recursos e degradação da natureza é preciso que cada um faça a sua parte para que juntos possamos mudar essa situação. Assim as empresas obtém lucros, a comunidade ganha com conhecimento e a natureza agradece, porém trabalhar a temática proposta no trabalho com os clientes do supermercado não foi tarefa fácil. Com relação às empresas e funcionários não há o que se ressaltar, pois são pessoas extremamente profissionais e prontas para ajudar, colaborando com o que fosse necessário para a conclusão desse trabalho. Já os clientes apresentavam certa resistência em responder as perguntas, poucos se mostraram interessados em contribuir com a pesquisa. Para entendimento e interpretação das respostas do questionário, teve-se que realizar pesquisas sobre o tema abordado desde o seu surgimento, seus componentes e a atualidade. Logo após o seu entendimento pode-se fazer a tabulação dos dados dos questionários.

A ferramenta do questionário mostrou-se adequada para os objetivos propostos. Possibilitou traçar o perfil do público-alvo dos supermercados, nos mostrando os seus comportamentos de compra e o conhecimento das pessoas sobre Marketing Ambiental.
Por outro lado, afora as dificuldades encontradas, os resultados da pesquisa são de grande importância, pois se trata de um trabalho de diagnóstico que nunca foi feito na COTRISEL e no Big Max, e que vai favorecer as empresas por adotarem medidas que chamem a atenção do consumidor e influencie na sua decisão de compra, e irá favorecer também o meio ambiente e, conseqüentemente, a comunidade porque conscientizando a população seus hábitos de consumo mudarão.

Assim, este estudo evidenciou que, tanto os funcionários das empresas em análise, quanto seus habituais consumidores ainda carecem de uma consciência ambiental e, como se viu, maior parte deles respondeu que se preocupa com estas questões, mas na prática, suas falas diferem ao demonstrar o seu comportamento de compra. Neste sentido é necessário que aos funcionários, consumidores e as direções das empresas, sejam promovidas ações tendentes a reeducação ambiental, bem como, aos dirigentes estabelecerem ações estratégicas no sentido de ampliar a oferta de produtos ecologicamente corretos, reforçando a propaganda em torno deles.

\section{Referências}

BAKER, Michael J. Administração de Marketing. 5. ed. Rio de Janeiro: Elsevier, 2005.

BERKOWITZ, Eric N.et al. Marketing. 6. ed. Rio de Janeiro: LTC, 2003. v. 1.

BOONE, Louis E. e KURTZ, David L. Marketing Contemporâneo. 8. ed. Rio de Janeiro: LTC, 1998.

BORGES, Gustavo da Rosa. Entendendo o Marketing. Pelotas: EDUCAT, 2006.

CECONELLO, Douglas P. COTRISEL: 50 anos de história: meio século ao lado do produtor rural. São Sepé, 2007.

CHURCHILL, Gilbert A.; PETER, J. Paul. Marketing: criando valor para clientes. São Paulo: Saraiva, 2000. 
COBRA, Marcos. Administração de Marketing. 2. ed. São Paulo: Atlas, 1992.

DIAS, Reinaldo. Marketing Ambiental: ética, responsabilidade social e competitividade nos negócios. São Paulo: Atlas, 2009.

ETZEL, L. Michael; WALKER, Bruce J.; STANTON, William J. Marketing. São Paulo: Makron Books, 2001.

KOTLER, Philip; ARMSTRONG, Gary. Princípios de Marketing. $7^{\text {a }}$ ed. Rio de Janeiro: Prentice-Hall do Brasil Ltda, 1998.

Princípios de Marketing. Rio de Janeiro: Prentice-Hall do Brasil Ltda, 1993.

. Marketing para organizações que não visam lucro. São Paulo: Atlas, 1978

KOTLER, Philip. Administração de Marketing: análise, planejamento, implementação e controle. 5. ed. São Paulo: Atlas, 2009.

LAS CASAS, Alexandre Luzzi. Marketing: conceitos, exercícios e casos. 3. ed. São Paulo: Atlas, 1993.

LEAL, Alzira Elaine Melo; SOUZA, Carlos Eduardo Gerson de. Construindo o conhecimento pela pesquisa: Orientação básica para elaboração de trabalhos científicos. Santa Maria: Sociedade Vicente Pallotti, 2006.

MELO NETO, Francisco Paulo de; FROES, César. Gestão da responsabilidade social corporativa: o caso brasileiro: da filantropia tradicional a filantropia de alto rendimento e ao empreendedorismo social. Rio de Janeiro: Qualitymark, 2001.

NICKELS, William G.; WOOD, Marian Burk. Marketing: Relacionamentos, qualidade, valor. Rio de Janeiro: LTC, 1999.

THOMPSON, Marjorie; PRINGLE, Hamish. Marketing Social: marketing para causas sociais e a construção das marcas. São Paulo: Makron Books, 